This is the author's final, peer-reviewed manuscript as accepted for publication. The publisher-formatted version may be available through the publisher's web site or your institution's library.

\title{
Impact of distributed generations with energy storage devices on the electric grid
}

Anurag K. Srivastava, Aarthi A. Kumar, Noel N. Schulz

\section{How to cite this manuscript}

If you make reference to this version of the manuscript, use the following information:

Srivastava, A. K., Kumar, A. A., \& Schulz, N. N. (2012). Impact of distributed generations with energy storage devices on the electric grid. Retrieved from http://krex.ksu.edu

\section{Published Version Information}

Citation: Srivastava, A. K., Kumar, A. A., \& Schulz, N. N. (2012). Impact of distributed generations with energy storage devices on the electric grid. IEEE Systems Journal, 6(1), 110-117.

Copyright: (C) 2012 IEEE

Digital Object Identifier (DOI): doi:10.1109/JSYST.2011.2163013

Publisher's Link: http://ieeexplore.ieee.org/xpl/articleDetails.jsp?arnumber=6140538

This item was retrieved from the K-State Research Exchange (K-REx), the institutional repository of Kansas State University. K-REx is available at http://krex.ksu.edu 


\title{
Impact of Distributed Generations with Energy Storage Devices on the Electric Grid
}

\author{
Anurag K Srivastava, Senior Member, IEEE, Aarthi A Kumar, Member, IEEE, Noel N Schulz, \\ Senior Member, IEEE
}

\begin{abstract}
The commonly used Distributed Generations (DG) technologies include wind generators, photovoltaics, and biomass generators with their sizes varying between several $\mathrm{kW}$ to a few MW. Energy storage devices are generally used to smooth variations in DG's MW output due to inherent unpredictability and to minimize exchange of power from grid. Connecting the storage and DG's to the grid have both technical and economic impacts. This paper aims at analyzing the technical and economic impacts of distributed generators along with energy storage devices on the distribution system. The technical analysis includes analyzing the transient stability of a system with DG's and energy storage devices, such as a battery and ultracapacitor. The DG's are represented by small synchronous and induction generators. Different types and locations of faults and different penetration levels of the DG's are considered in the analysis. Energy storage devices are found to have a positive impact on transient stability. For economic analysis, the costs of the system with different DG technologies and energy storage devices are compared using the software tool "Hybrid Optimization Model for Electric Renewables (HOMER)". Finally the analysis for cost versus benefits of DG's and energy storage devices is compared briefly.
\end{abstract}

Index Terms - Batteries, system economics, energy storage devices, power system transient stability, distributed generation, ultracapacitors.

\section{INTRODUCTION}

$\mathrm{T}$ here have been increased focus in the recent years on the concept of smoothing intermittent output of distributed generation (DG) using energy storage [1]. DG's can be defined as the concept of connecting generating units of small sizes, between several $\mathrm{kW}$ to a few MW. The primary source of energy for these generators can be the traditional nonrenewable sources such as gas or the renewable sources such as wind, solar, hydro, and biomass [2]. These generators are connected either to the medium voltage or low voltage sections of the electric grid. Most often they are connected near the load centers or the low voltage networks.

In case of certain renewable technologies, such as wind turbines and solar panels, the output power depends upon the

Anurag K Srivastava is with the School of Electrical Engineering and Computer Science, Washington State University, USA (e-mail: asrivast@eecs.wsu.edu).

Aarti A Kumar is with LCG Consulting, Los Altos, CA, 94022, USA (email: aarthiasokkumar@gmail.com).

Noel N Schulz is with Department of Electrical and Computer Engineering, Kansas State University, Manhattan, KS, USA 66506 (e-mail: noels(ksu.edu). availability of renewable resource and therefore may not always be constant. In such cases, in order to augment the DG's during low power periods, energy storage devices are used [3]. Other than wind and solar, storage can help in smoothing the power in conjunction with biomass especially for rural CHP (combined heating and power) applications. These devices store energy during periods of high power or low demand and use the stored energy to supply the excess loads during periods of low power. Different types of energy storage devices that are used in a distributed environment include batteries, ultracapacitors, flywheels, fuel cells and superconducting magnetic energy storage (SMES) [4]-[7]. In addition to supporting the DG's during peak demand, the storage devices may also help in improving the overall stability of the entire system. These energy storage devices are connected to the electric grid by means of suitable power conversion devices [8]-[10].

Though the primary purpose of the DG's is to supply the local demand of electricity, in cases where energy production exceeds the local demand, DG's can be interconnected to the electric grid thereby supplying the excess power. Distributed generation impacts the overall grid and distribution system either positively or negatively depending upon various factors, such as the size and type of system and loads. Dynamic modeling and simulation are needed to assess the impact [11], [12]. Researchers have presented the microturbine modeling and impact of DG's and power management through control strategy using STATCOM [13], [14]. Effect of nonlinear loads on electric grid with DG was studied in [15]. The major technical impact of the DG interconnection is on the stability of the system [16], [17]. Connecting a DG/energy storage device to the grid system affects the transient as well as steady state stability of the entire system [18]. To study the impact of energy storage device on the electric grid, an interface and storage model needs to be developed along with a dynamic model of DG and power system grid/distribution system. Battery and ultracapacitors models including their control have been discussed in [19]-[26]. Most of the work presented in the literature examines effects of DG on the grid, but very few have focused on DG/energy storage effects on grid.

The research work presented here aims at analyzing both the technical and economic impacts of connecting DG's and energy storage devices to a grid/distribution system. For the technical analysis, a small 8 bus system has been built in MATLAB/Simulink [27]. The DG's are represented by small synchronous and induction generators. The transient stability of this system is analyzed by means of certain transient stability indicators. Case studies by varying penetration levels 
of the DG's as well as types and locations of faults are considered in the analysis. Focus of this study is system level studies and develop framework for technical and economic impact of DG/ storage. The economic analysis is done using software called "Hybrid Optimization Model for Electric Renewables (HOMER)" developed by National Renewable Energy Laboratory (NREL). HOMER is a computer model to evaluate design options and economic feasibility for both offgrid and grid-connected power systems [28]. The total costs of system, with different DG technologies and types of energy storage devices have been calculated and compared. Finally the cost versus benefits of various technologies and energy storage devices are analyzed and results are presented.

The test system used in the study is explained in the Section II. Section III presents the modeling of the two energy storage devices, a battery and ultracapacitor. The transient stability study of the system and its results are presented in Section IV. Economic analysis using HOMER and the results are discussed in Section V. Finally the conclusions are presented in Section VI.

\section{DESCRIPTION OF THE TEST SYSTEM}

The size and type of the test system play a very vital role in the analysis of the transient stability. A large system may increase the time and complexity of the analysis whereas a small system may lead to neglecting necessary factors. Therefore a medium sized representative 8-bus system has been chosen for the study. The one line diagram of the test system is shown in Fig. 1 very similar to typical distribution system and the characteristics of the test system are given in Table I.

\section{TABLE I}

\section{CHARACTERISTICS OF THE TEST SYSTEM}

\begin{tabular}{|l|c|}
\hline \multicolumn{1}{|c|}{ System characteristics } & Value \\
\hline Total number of buses & 8 \\
\hline Total number of sources: & 4 \\
$-\quad$ Main source & 1 \\
- Distributed sources/Storage & 3 \\
\hline Number of loads: & 15 \\
$-\quad$ RL loads & 9 \\
$-\quad$ Induction motors & 6 \\
\hline Total number of transformers & 2 \\
\hline
\end{tabular}

The system consists of a main source, which is connected to bus 1 at a voltage level of $12.47 \mathrm{kV}$ and three distributed generators connected to buses 4,5 and 8 . The DG's connected to buses 4 and 5 are represented by synchronous generators and the DG that is connected to bus 8 is represented by an induction generator. Storage devices (battery or ultracapacitors) were connected to same buses as DG interfaced with power conditioning devices [20,31]. Buses 4 and 5 are at a voltage level of $4.157 \mathrm{kV}$ and bus 8 is at lower voltage level of $1.01 \mathrm{kV}$. Three sets of loads are connected to each of the buses 4,5 and 8. Each set of loads consists of induction motors and RL loads.

Synchronous generator, transformer, loads and induction generator models have been taken with typical values in MATLAB/ Simulink. Modeling parameters are shown in references [29]. Standard built-in models of governors and exciters of the generators are used from the power systems library in Simulink.

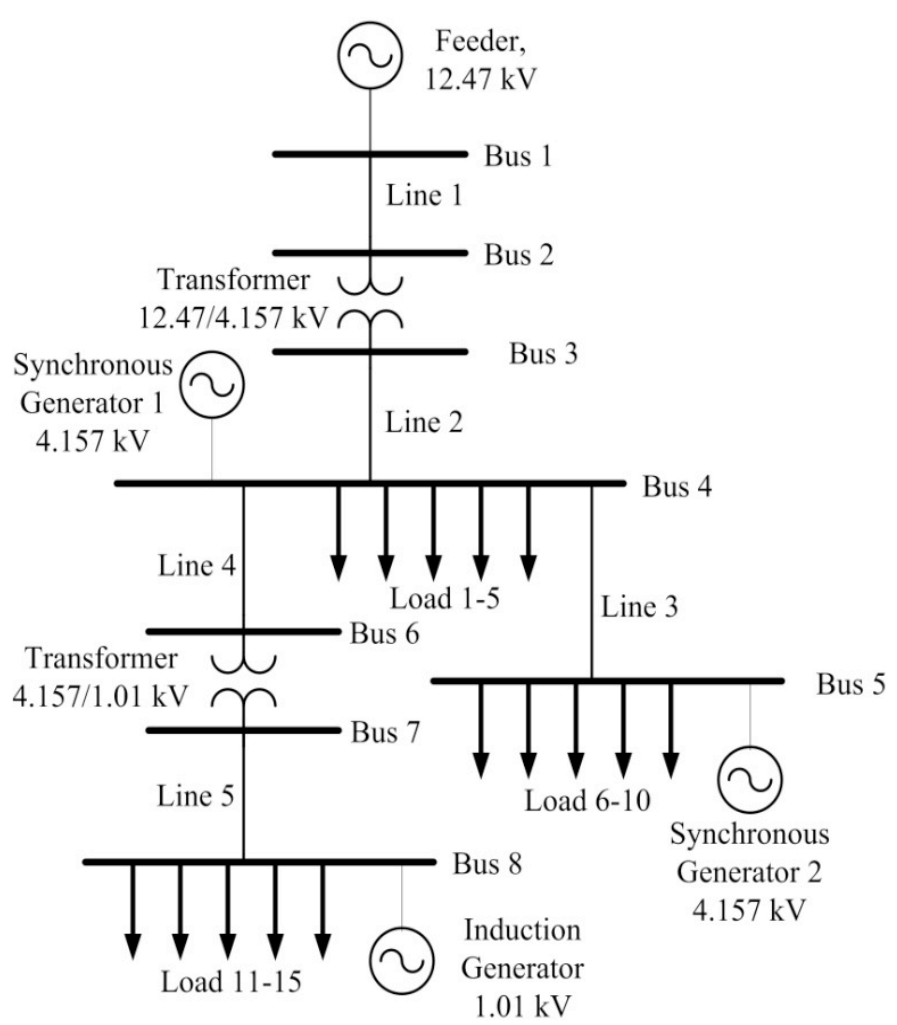

Fig. 1. One line diagram of the 8-bus test system

\section{MODELING OF THE STORAGE DEVICES}

Since there are no models of energy storage devices in the library, basic models of the battery and ultracapacitor retaining required characteristic have been developed in Simulink and have been used for the study. The modeling of the battery and the ultracapacitor are explained in this Section. Basic characteristic and performance analysis of modeled storage devices are available in [29].

\section{A. Battery}

In this study linear model of the battery is used. The equivalent circuit of the linear battery is as shown in Fig. 2.

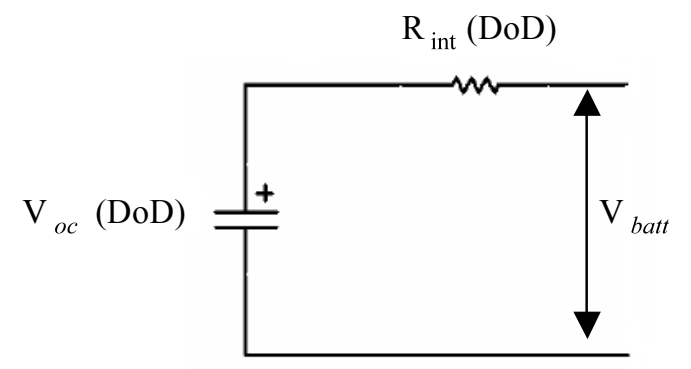

Fig. 2. Equivalent circuit model of a battery

The following equations of the battery are obtained from the equivalent circuit.

$\mathrm{V}_{b a t t}=\mathrm{V}_{o c}(\mathrm{DoD})+\mathrm{I}_{B} \mathrm{R}_{\text {int }}(\mathrm{DoD})$ 


$$
\begin{aligned}
& \mathrm{DoD}=\frac{1}{Q_{\max }} \int I_{B} \mathrm{tdt} \\
& \mathrm{SOC}=\frac{Q_{\max }-Q_{\text {used }}}{Q_{\max }}=1-\mathrm{DoD} \\
& \mathrm{R}_{\text {int }}=0.20139+0.58863 \mathrm{DoD}-0.81697(\mathrm{DoD})^{2} \\
& +0.79035(\mathrm{DoD})^{3} \\
& \mathrm{~V}_{o c}=3.95587-1.42918 \mathrm{DoD}+2.83095(\mathrm{DoD})^{2} \\
& -3.7497(\mathrm{DoD})^{3} \\
& \text { Where, } \\
& \mathrm{V}_{\text {batt }}=\text { Terminal voltage of the battery }(\mathrm{V}) \text {, } \\
& \mathrm{I}_{B} \quad=\text { Curent flowing through the battery (A), } \\
& \mathrm{Q}_{\max }=\text { Maximum battery capacity at fully } \\
& \text { charged/discharged conditions (Ah), } \\
& \mathrm{Q}_{\text {used }}=\text { Used battery capacity (Ah) }
\end{aligned}
$$

Depth of Discharge (DoD) is an alternate method to indicate a battery's State of charge (SOC). The DoD is the inverse of SOC. The empirical formula governing the relationship between $\mathrm{R}_{\text {int }}$ and $\mathrm{DoD}$ as well as $\mathrm{V}_{o c}$ and DoD were obtained from experiments based on [19].

Based on the equivalent circuit and the corresponding equations, the model of the battery was designed in Simulink.

\section{B. Ultracapacitor}

Using the first order linear circuit, the model of the ultracapacitor is developed similar to that of the battery. The model that has been selected represents only the electrical properties of the cell and neglects most of the chemical properties. Fig. 3 shows the equivalent circuit of the ultracapacitor [26].

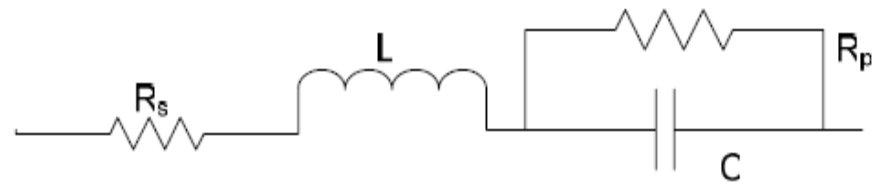

Fig. 3. Equivalent circuit of the ultracapacitor

The following equations of the ultracapacitor are obtained from the equivalent circuit shown in Fig. 3.

$$
\begin{aligned}
& \mathrm{V}_{c a p}=\mathrm{V}_{c}-\left(\mathrm{R}_{s} \mathrm{I}_{c a p}\right)-\left(\mathrm{L} \frac{d i}{d t}\right) \\
& \mathrm{V}_{c}=\mathrm{V}_{c i}-\left(1 / C \int I_{c} \mathrm{dt}\right) \\
& \mathrm{I}_{c}=\mathrm{I}_{c a p}+\mathrm{I}_{L}
\end{aligned}
$$

$$
\begin{aligned}
& \mathrm{I}_{L}=\frac{V_{c}}{R_{p}} \\
& \mathrm{SOC}=1-\left(1 / Q_{\text {rated }} \int I_{\text {cap }} \mathrm{dt}\right)
\end{aligned}
$$

Where,

$\mathrm{V}_{\text {cap }}$ - Operating voltage of the ultracapacitor (V)

$\mathrm{V}_{c}-$ Voltage across the capacitor $(\mathrm{V})$

$\mathrm{V}_{c i}$ - Initial voltage across the capacitor $(\mathrm{V})$

$\mathrm{I}_{\text {cap }}$ - Ultracapacitor current (A)

$\mathrm{I}_{c}$ - Current through the capacitor (A)

$\mathrm{I}_{L}-$ Current through the parallel resistor (A)

$\mathrm{Q}_{\text {rated }}-$ Rated max. capacity of the ultracapacitor $(\mathrm{Ah})$

SOC - State of charge of the ultracapacitor

Based on the first order model and the corresponding equations that were presented, a model of the ultracapacitor is developed in Simulink using the control system components in the Simulink library.

\section{TECHNICAL ANALYSIS}

Transient disturbances such as faults, load switching and load shedding might result in the change of system states and may lead to system instability. System disturbance indicators generally used for transient stability are rotor angle, rotor speed, terminal voltage and frequency [16], [17]. The type and size of the DG's or storage present in the system can influence the magnitude and frequency of these oscillations.

\section{A. Transient Stability Indicators}

The transient stability of a system can be assessed by means of certain indicators [30]. In this study, four different indicators have been chosen to analyze the stability of the test system. The four transient stability indicators chosen are:

a) Rotor Speed deviation - is the maximum amount of deviation in the rotor speed during fault.

b) Oscillation duration - is the time taken by the oscillations to reach a new equilibrium after the clearance of the fault.

c) Rotor angle - The response of the rotor angle of the generator to different types of faults is considered.

d) Terminal voltage - The variation in the terminal voltage of the DG due to different fault conditions is monitored. The voltage stability is analyzed by taking into consideration the drop in voltage level during fault and the time taken by it to settle down after the clearance of the fault.

\section{B. Test Scenarios}

Taking into consideration the factors that affect the transient stability, different scenarios for the study were developed and are listed in Table II.

First, impacts of DG on grid stability were studied and then effects of DG with storage were studied. As shown in the Table II, three different test scenarios were selected, which involve different load and generation levels to show the effect of equal and unequal load/generation size. 
TABLE II

TEST SCENARIOS

\begin{tabular}{|c|c|c|c|c|c|c|}
\hline $\begin{array}{c}\text { Test } \\
\text { case }\end{array}$ & $\begin{array}{c}D G 1 \\
(\%)\end{array}$ & $\begin{array}{c}D G 2 \\
(\%)\end{array}$ & $\begin{array}{c}D G 3 \\
(\%)\end{array}$ & $\begin{array}{c}\text { Load1 } \\
(M V A)\end{array}$ & $\begin{array}{c}\text { Load2 } \\
(M V A)\end{array}$ & $\begin{array}{c}\text { Load3 } \\
(M V A)\end{array}$ \\
\hline Case I & Equal & Equal & Equal & 15 & 15 & 15 \\
\hline Case II & Equal & Equal & Equal & 27 & 9 & 9 \\
\hline Case III & $50 \%$ & $25 \%$ & $25 \%$ & 15 & 15 & 15 \\
\hline
\end{tabular}

In each case the penetration levels of the DG's varied depending upon the load. Penetration level of the DG is given by,

Penetration level of DG $=\frac{\sum P_{D G}}{\sum P_{\text {load }}} 100$

Where,

$P_{D G}$ - Total power delivered by all the DG's together

$P_{\text {load }}$ - Total load demand

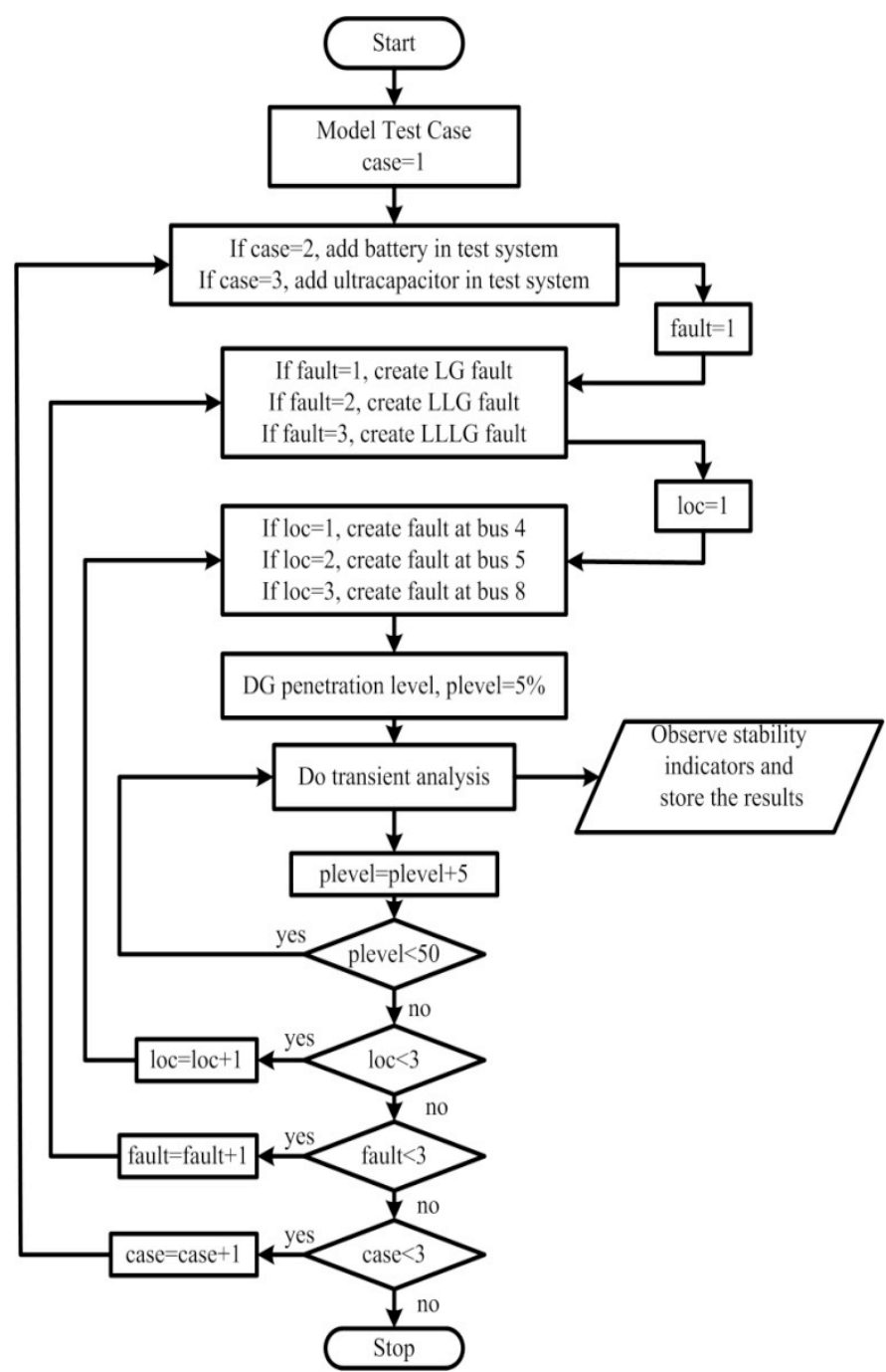

Fig. 4. Flowchart for transient stability analysis

In Case I, the DG's are considered to supply equal amounts of power to the loads, which are equally distributed. In Case II, the loads are unequally distributed. Load 1 is 27 MVA and load 2 and load 3 are of 9 MVA each. These unequal sets of loads are supplied by the three generators equally. In case III, the loads are equal whereas the generators supply unequal amounts of power with DG1 supplying $50 \%$ of the load and DG's 2 and 3, supplying $25 \%$ each of the required power.

In all the different scenarios, we apply three different types of faults, L-G, L-L-G and three phase faults (L-L-L-G).

\section{Test Procedure}

A step by step approach, as shown in the Fig. 4, has been followed to analyze the transient stability:

- A fault is applied at a one of the three buses of the system as mentioned in the scenario. The duration of the fault is $100 \mathrm{~ms}$ after which it is considered to be cleared automatically. The fault is applied at $1.5 \mathrm{sec}$ and cleared at $1.6 \mathrm{sec}$.

- The penetration level of the DG is varied from $5 \%$ to $50 \%$. The MVA of the generators is changed based on the penetration level.

- The response of the system to the fault is analyzed by means of the transient stability indicators that were chosen.

- This procedure is repeated for different types and locations of faults with varied penetration levels of the DG.

- After the analysis without energy storage devices, the transient stability with energy storage devices needs to be done.

- The energy storage devices are connected to the system by means of the suitable power electronic converter [20, 31].

- About $10 \%$ of the DG power is considered as size of the storage devices [32].

- The process of analyzing stability is repeated as done earlier for the system without energy storage devices.

- The responses of the indicators to the fault are analyzed for the system with energy storage devices.

D. Results of the analysis with and without energy storage devices

Responses of the four different indicators to different types of faults and different penetration levels of the DG are analyzed for faults at buses 4,5 and 8 (refer Fig. 1). The responses of each of the indicators are observed.

\section{Rotor Angle}

When a fault is applied to the system the rotor angle starts increasing and once the fault is cleared the rotor angle starts to decrease and settles back to a constant value. The stability of the system is assessed based on the amount of change in the rotor angle during fault. From the results obtained it was observed that the change in rotor angle during fault is less with $50 \%$ penetration level of DG compared to that with a $10 \%$ penetration level irrespective of the type of fault, location of fault, the load and generation conditions and whether the energy storage devices are connected or not. Stability of a given system is inversely proportional to change in the rotor angle [30]. This shows that with more penetration level of the DG, the stability of the system increases. 


\section{Terminal Voltage}

There is a drop in terminal voltage when a fault is applied to the system and once the fault is cleared, the terminal voltage rises back and settles back to its normal value. The transient stability in this case can be assessed taking into consideration the amount of drop in terminal voltage during the period of fault and also the time taken by the voltage to settle back to its normal value once the fault is cleared. Similar to the previous indicator, in this case also, the drop in terminal voltage was seen to decrease with increase in the penetration levels of the DG's which shows that the stability of the system is better with higher penetration level case compared to that of lower penetration levels [30]. This result was seen to be true for the different types and locations of the fault for the three different load and generation conditions and either with or without the energy storage devices also.

\section{Rotor speed deviation and Oscillation duration}

Analysis of the rotor speed deviation and the oscillation duration also showed similar results as the previous two cases where the increase in penetration level of the DG's increases the transient stability of the system.

These results are not presented here because of space limitations but are available in reference [29]. Though in general, we were able to observe that the stability was seen to improve in all the cases, the analysis of the impacts of the different factors on the stability has to be closely analyzed.

\section{Effect of different fault types}

The type of fault plays a significant role in the stability of the system. This can be seen from Fig. 5, which shows the comparison of the three types of faults (L-G, L-L-G and 3phase) on the rotor speed deviation of the system with and without energy storage devices and with $30 \%$ penetration level of the DG and fault at bus 4 .

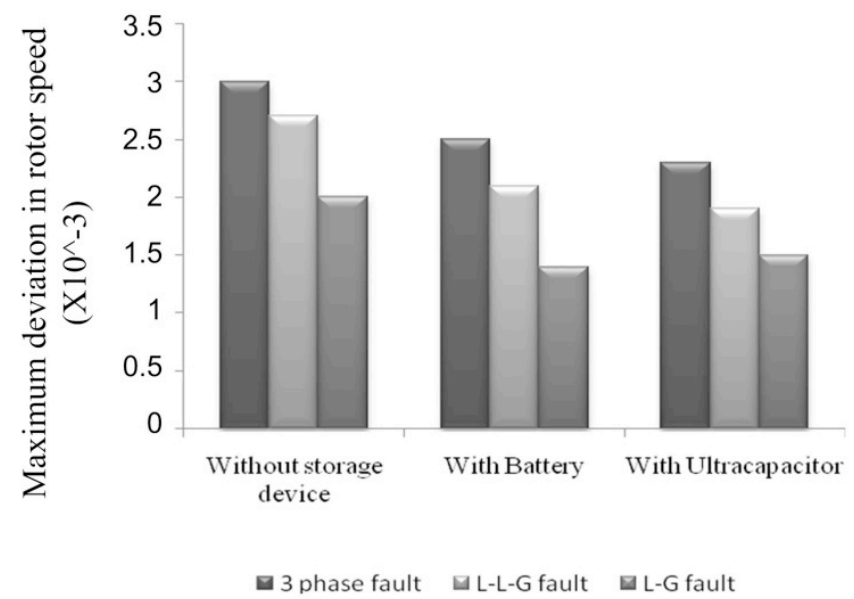

Fig. 5. Comparison of impacts of different types of faults at bus 4 (Case I)

The comparison shows that the three-phase fault at bus 4 results in more deviation in the rotor speed compared to the other two types of fault in the absence of a storage device or with a battery or an ultracapacitor. The L-G fault causes the least deviation among the three types of faults in all the three conditions. This implies that the stability of the system is better with an L-G fault when compared to a three phase fault.

This trend was found in all the scenarios with different load and generation conditions, with the presence or absence of the storage device and with the two types of storage devices. This validates that the transient stability is better for a less severe fault compared to a more severe fault. This can also be observed from figure 5 , that the transient stability is better with storage devices.

\section{Impacts of different fault locations}

Similar to the type of fault, the location of a fault also impacts the transient stability of a system. A comparison of the impact of a three-phase fault at different locations on the rotor speed deviation is given in Fig. 6 .

Fig. 6 shows that a fault at bus 4 causes more deviation in rotor speed than a fault at bus 5 or at bus 8 . This is seen even in cases in which a battery or an ultracapacitor are connected to the system. This implies that the stability of the system is better, when faults are at bus 8 and it is the worst when faults are at bus 4 . This holds true for most of the cases, which depends on specific location of bus in proximity to source.

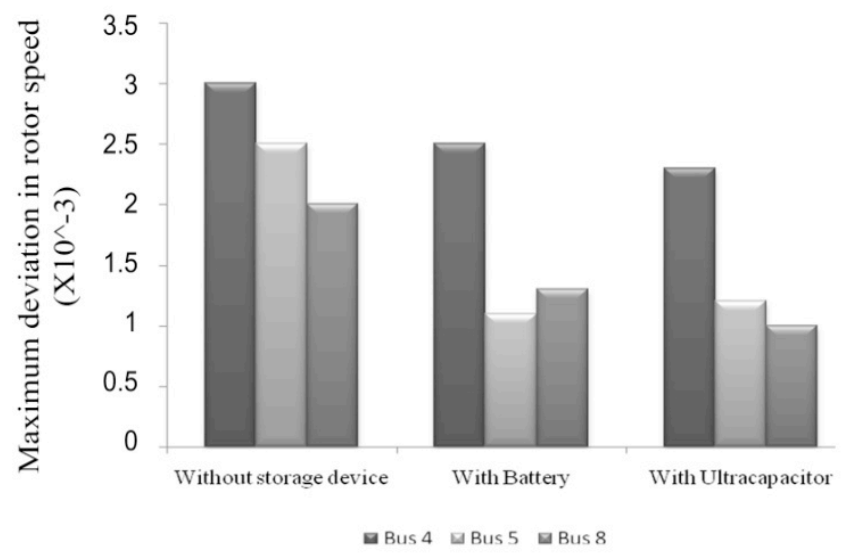

Fig. 6. Comparison of impacts of different locations of a threephase fault (Case I)

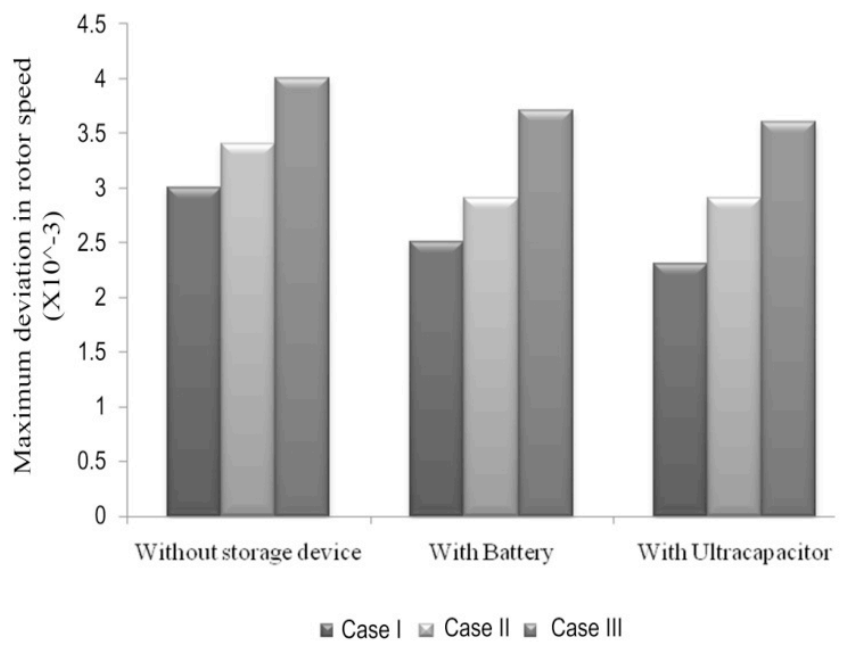

Fig. 7. Comparison of impacts of different load and generation conditions 
Analysis on the results obtained shows that the distance of the fault from the main source affects the level of stability. If the fault is close to the main source, the transient stability is less compared to the transient stability when faults are at buses far from the main source.

\section{Effect of different generation and load conditions}

As seen in Fig. 7, case I (loads are equal and the DG's supply equal amounts of power), results in less deviation in the rotor speed compared to the other two cases of unequal load and unequal generation conditions respectively. Similar results were observed for all the other indicators and also for conditions with battery and energy storage devices.

\section{Impacts of storage devices}

In all the cases observed previously it was clearly seen that the stability of the system changes with the addition of the energy storage devices. In this study we have considered two different types of energy storage devices namely battery and ultracapacitor. Fig. 8 shows the comparison of the maximum deviation in rotor speed due to a three phase fault at bus 4, without any storage device, with a battery and with an ultracapacitor.

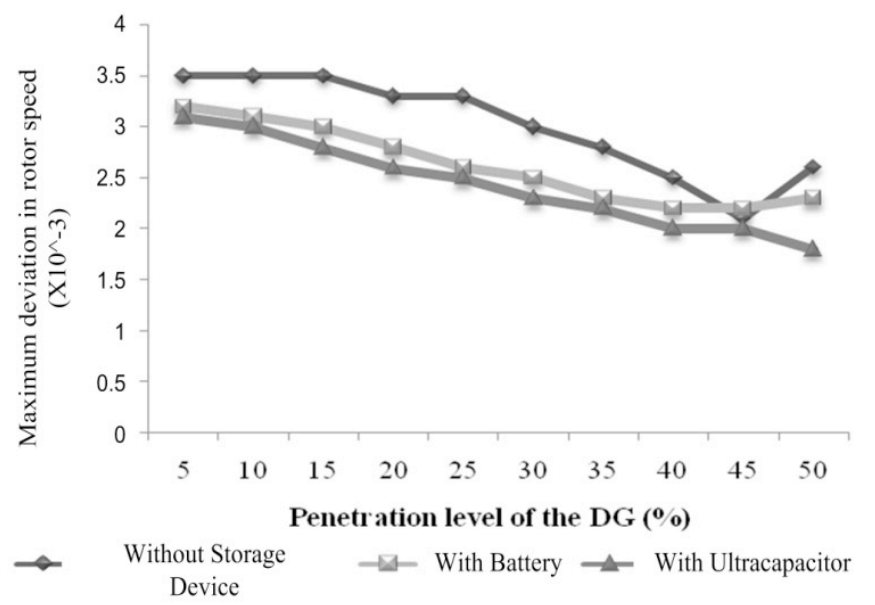

Fig. 8. Comparison of impacts of storage devices on rotor speed deviation

It can be clearly seen that with the addition of an energy storage device, the maximum deviation in rotor speed decreases which implies that the transient stability improves. For the two energy storage devices, adding an ultracapacitor to the system seemed to improve the stability more than the addition of a battery. But on the contrary, Fig. 9 shows that addition of the battery has better stability than the addition of the ultracapacitor in terms of oscillation duration. Stability of the system is a very nonlinear phenomenon and depends on available energy, rate of energy and inertia of the component. Due to these characteristics, a battery and ultarcapacitor may have different impacts on the system stability parameters. In general the analysis showed that the addition of a storage device to the system increases its transient stability.

It was also seen that in a majority of the cases the stability of the system increases as the penetration level of the DG increases, but after a certain percentage it saturates or starts decreasing. This level is considered as the optimal penetration level of the DG and it depends upon the size and type of system and various other factors.

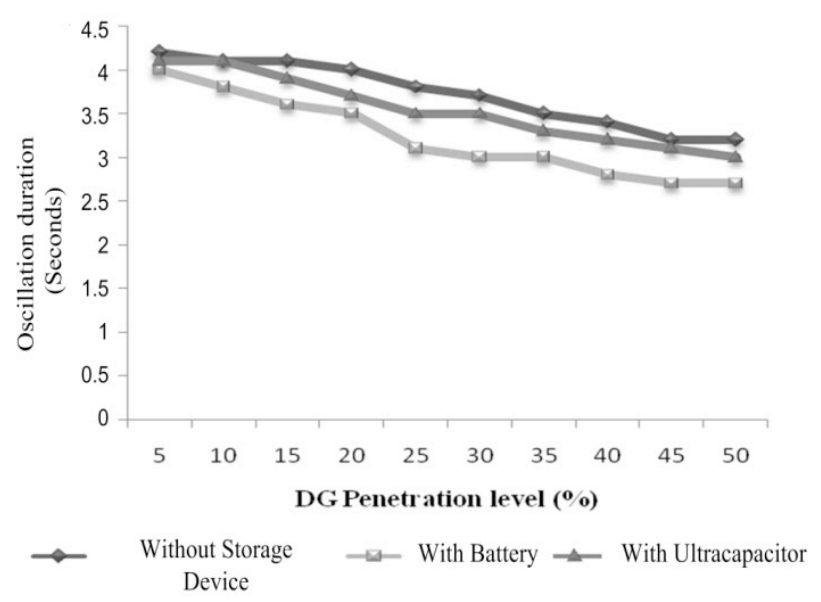

Fig. 9. Comparison of impacts of storage devices on oscillation duration

DG power help in stability by providing needed energy to keep up with required energy for disturbances. But if the power provided by DG is more than some threshold then it may cause problems. From the analysis, based on Fig. 8, 9, and $10,45 \%-50 \%$ was observed to be the ideal penetration level of the DG for the 8-bus test system. This threshold may vary for different system. Also analyzing the impact of location of storage will be useful in future.

\section{ECONOMIC ANALYSIS}

The purpose of the economic analysis in this study is to compare the total cost of a system without energy storage devices and with a battery and an ultracapacitor. Hybrid Optimization Model for Energy Renewables (HOMER) is the software that has been used for the cost analysis of the system with distributed generators and energy storage devices.

\section{A. Description of the system in HOMER}

The main components of the system are the distributed generators, electric grid, energy storage devices, converter and the loads. The capital cost, cost of operation, maintenance, fuel and other costs contribute to the total cost of the system. Additional details for input and output data used with HOMER is described in [29].

\section{a) Distributed generators}

It was seen from the technical analysis that the ideal penetration level of the DG for the test system was $45 \%-50 \%$. Therefore in the economic analysis we consider a penetration level of $48 \%$ for the distributed generators. In this study three different DG technologies have been considered.

Diesel generator - The capital cost of the diesel generator is typically between $\$ 250$ and $\$ 500$ per $\mathrm{kW}$ and the replacement cost is between $\$ 150$ and $\$ 300$ per $\mathrm{kW}$. Cost of diesel is taken to be $\$ 0.8$ per liter. The operation and maintenance cost of the 
generator is $\$ 0.001$ per $\mathrm{kW}$ [33]. The cost decreases with increasing capacity of the generators. Since the capacity of the DG is quite large in our case, costs involved are taken on the lower scale.

Wind turbines - The capital cost of the wind turbine are higher than that of the diesel generators. It generally ranges between $\$ 900$ and $\$ 1000$ per $\mathrm{kW}$. The replacement cost is about $15-20 \%$ of the original cost and the O\&M cost is about $3 \%$ of the original cost [34], [35]

Biomass generators - The capital cost of the biomasspowered generator is about $\$ 1725$ per $\mathrm{kW}$ [36]. This includes the cost of the gasifier, generator and transportation cost.

\section{b) Electric Grid}

The system is grid connected and therefore a part of the load is considered to be supplied by the grid. The cost of buying power from the grid is selected to be $0.01 \$ / \mathrm{kW}$ based on reference [33].

\section{c) Battery}

The capital and replacement costs of a lithium ion battery are $\$ 200$ and $\$ 175$ per $\mathrm{kW}$, respectively. The O\&M cost of the Li-ion battery is $\$ 25 / \mathrm{kW}$ per year [4].

\section{d) Ultracapacitor}

Unlike the battery, there is no existing model of ultracapacitor in HOMER. Therefore a battery model, but with the data corresponding to that of an ultracapacitor is chosen. The capital cost of ultracapacitors is about $\$ 30,000$ per $\mathrm{kW}$ and in case of mass productions it is $\$ 25,000$ per $\mathrm{kW}$. There is no replacement cost involved for the ultracapacitors. The O\&M cost is about $\$ 5 / \mathrm{kW}$ per year [4].

\section{e) Converter}

The energy storage devices supply DC power which needs to be connected to an AC grid. The cost of the power conversion system (PCS) depends on the period of power storage and in turn depends on the type of technology. PCS cost for ultracapacitor is taken higher than battery based on [4] as PCS for ultracapacitor should be able to withstand high rate of charging/discharging for ultracapacitor. The cost of a PCS for a Li-ion battery system is $\$ 200$ per $\mathrm{kW}$ and for that of the ultracapacitors is $\$ 300$ per $\mathrm{kW}$ [4].

\section{B. Simulation procedure}

For the simulation, three different cases are considered. Each of the cases includes three different subsystems which are as listed below:

1. Diesel generator system

- Without storage devices

- Diesel-battery system

- Diesel-ultracapacitor system

2. Biomass generator system

- Without storage devices

- Biomass-battery system

- Biomass-ultracapacitor system

3. Wind turbine system

- Without storage devices

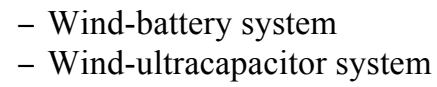

The nine different cases, which include different combinations of DG's and storage devices, were simulated and the net present cost of the combinations is found out. The capital, replacement and O\&M costs of the DG are calculated for this capacity. In all the cases, which include energy storage devices, $10 \%$ of the DG power is considered to be supplied by the storage devices. The net present cost of the system for all the cases is calculated based on the HOMER simulation. This cost includes the capital cost, replacement cost, fuel costs and all other costs that are involved for the entire period of the project.

\section{Result Analysis}

Comparison of net present values of different cases with different DG technologies with and without energy storage devices is presented in the Table III.

It can be seen that in case of the diesel generator system, the total cost of the system decreases when an energy storage device is added to it. High cost of diesel mainly contributes towards total cost of running the system. Storing the energy and using when needed avoids high fuel cost of diesel to cause the total cost go down for diesel generator with energy storage. Between the two types of storage devices, the cost of diesel-battery system was less compared to the diesel ultracapacitor system. This is due to the higher cost of the ultracapacitors. The total cost of the system with the other two DG techniques is not as less as the diesel system.

From the results of the economic analysis, it can be seen that energy storage devices in the system reduce the net present cost for a diesel generator due to lesser fuel cost. Costs of wind and biomass system are not as low as the diesel system. Existing biomass generation is not economical.

TABLE III

\section{COMPARISON OF NET PRESENT VALUES OF DIFFERENT CASES}

\begin{tabular}{|c|c|c|c|}
\hline & $\begin{array}{c}\text { Without } \\
\text { storage } \\
\text { device }\end{array}$ & $\begin{array}{c}\text { With } \\
\text { Battery }\end{array}$ & $\begin{array}{c}\text { With } \\
\text { Ultracapacitor }\end{array}$ \\
\hline $\begin{array}{c}\text { Diesel } \\
\text { generator }\end{array}$ & $\$ 6,903,679$ & $\$ 4,970,905$ & $\$ 5,152,033$ \\
\hline $\begin{array}{c}\text { Wind } \\
\text { turbine }\end{array}$ & $\$ 6,627,833$ & $\$ 6,946,909$ & $\$ 7,222,969$ \\
\hline $\begin{array}{c}\text { Biomass } \\
\text { generator }\end{array}$ & $\$ 14,065,636$ & $\$ 15,163,446$ & $\$ 15,413,046$ \\
\hline
\end{tabular}

\section{CONCLUSIONS}

This research work focuses on analyzing the transient stability of a system with both energy storage devices and distributed generators. The transient stability of the test system was analyzed based on four stability indicators. The responses of the indicators to various simulation scenarios were observed. The different scenarios include different types and locations of faults and different penetration levels of the distributed generators. This study was done for a system with 
and without energy storage devices. An economic study for the net present costs of systems with both the energy storage devices was also analyzed.

The result analysis suggests that energy storage devices in the system along with distributed generators can improve the transient stability of the system. These results are for typical distribution feeder and cannot be extended for any configuration of distribution system. The impact on transient stability is system specific and depends on the location and type of disturbances. Ultracapacitors and biomass technologies need to be more economical to be cost effective for increased benefits. Future studies will include studying the impact of different types of battery models and other storage devices using developed framework for analysis.

\section{ACKNOWLEDGMENT}

The authors are thankful to the U.S. Department of Energy, Sustainable Energy Research Center and Micro CHP center at Mississippi State University for providing financial support for this research work.

\section{REFERENCES}

[1] M. Korpaas, A. T. Holen and R. Hildrum "Operation and sizing of energy storage for wind power plants in a market system", International Journal of Electrical Power \& Energy Systems, vol. 25, issue 8, pp. 599606, October 2003

[2] A.-M. Borbely and J. F. Kreider, "Distributed Generation - The power paradigm for the new millennium", edited book, CRC press LLC, 2001.

[3] G.O. Cimuca, C. Saudemont, B. Robyns, M.M. Radulescu, "Control and Performance Evaluation of a Flywheel Energy-Storage System Associated to a Variable-Speed Wind Generator," IEEE Trans. on Industrial Electronics, vol. 53, no. 4, pp. 1074- 1085, August 2006.

[4] S. M. Schoenung and W. V. Hassenzahl, "Long- Vs short term energy storage technologies analysis - A life cycle cost study - A study for the DOE energy storage systems program", A report presented by The Sandia National Laboratories, Aug 2003.

[5] Jiabin Wang, Weiya Wang, G.W. Jewell, D. Howe, "Design of a miniature permanent-magnet generator and energy storage system," IEEE Trans. on Industrial Electronics, vol. 52, no. 5, pp. 1383- 1390, Oct 2005.

[6] S. Lemofouet, A. Rufer, "A Hybrid Energy Storage System Based on Compressed Air and Supercapacitors With Maximum Efficiency Point Tracking (MEPT)," IEEE Trans. on Industrial Electronics, vol. 53, no. 4, pp. 1105-1115, August 2006.

[7] P. Thounthong, S. Rael, B. Davat, "Control Strategy of Fuel Cell and Supercapacitors Association for a Distributed Generation System," IEEE Trans. on Industrial Electronics, vol. 54, no. 6, pp. 3225-3233, Dec 2007.

[8] J.M. Carrasco, L.G. Franquelo, J.T. Bialasiewicz, E. Galvan, R.C. PortilloGuisado, M.A.M. Prats, J.I. Leon, N. Moreno-Alfonso, "PowerElectronic Systems for the Grid Integration of Renewable Energy Sources: A Survey," IEEE Trans. on Industrial Electronics, vol. 53, no. 4, pp. 1002- 1016, August 2006.

[9] J. Selvaraj, N. A. Rahim, "Multilevel Inverter For Grid-Connected PV System Employing Digital PI Controller," IEEE Trans. on Industrial Electronics, vol. 56, no. 1, pp. 149-158, Jan 2009

[10] S. Alepuz, S. Busquets-Monge, J. Bordonau, J. Gago, D. Gonzalez, J. Balcells, "Interfacing Renewable Energy Sources to the Utility Grid Using a Three-Level Inverter," IEEE Trans. on Industrial Electronics, vol. 53, no. 5, pp. 1504-1511, Oct 2006.

[11] H. Dagdougui, R. Minciardi, A. Ouammi, M. Robba, R. Sacile, "A Dynamic Decision Model for the Real-Time Control of Hybrid Renewable Energy Production Systems," IEEE Systems Journal, vol. 4, no. 3, p. 323, September 2010.

[12] J.T. Bialasiewicz, "Renewable Energy Systems With Photovoltaic Power Generators: Operation and Modeling," IEEE Trans. on Industrial Electronics, vol. 55, no. 7, pp. 2752-2758, July 2008.
[13] S. Grillo, S. Massucco, A. Morini, A. Pitto, F. Silvestro, "Microturbine Control Modeling to Investigate the Effects of Distributed Generation in Electric Energy Networks," IEEE Systems Journal, vol. 4, no. 3, p. 303, September 2010.

[14] S. Mohod, M. Aware, "A STATCOM-Control Scheme for Grid Connected Wind Energy System for Power Quality Improvement," IEEE Systems Journal, vol. 4, no. 3, p. 346, September 2010.

[15] R.A. Mastromauro, M. Liserre, A. Dell'Aquila, "Study of the Effects of Inductor Nonlinear Behavior on the Performance of Current Controllers for Single-Phase PV Grid Converters," IEEE Trans. on Industrial Electronics, vol. 55, no. 5, pp. 2043-2052, May 2008

[16] A. M. Azmy, I. Erlich, "Impact of distributed generation on the stability of electrical power systems", Proceedings of the IEEE Power engineering society general meeting, vol. 2, pp 1056-1063, Jun 2005.

[17] J. G. Slootweg and W. L. Kling, "Impacts of distributed generation on power system transient stability", Proceedings of the IEEE Power engineering society summer meeting, vol. 2, pp 862 - 867, Jul 2002.

[18] A. A. Kumar, A. K. Srivastava and N. N. Schulz, "Impact of biomass based distributed generation and energy storage devices on the grid", Proceedings of the Power system conference, Clemson, SC, March 2006.

[19] S. A. Khateeb, M. M. Farid, R. S. J and S. Al-Hallaj, "Mechanicalelectrochemical modeling of Li-ion battery designed for an electric scooter" Journal of Power Sources, vol. 158, pp 673 - 678, 2006.

[20] B. Singh, A. Adya, A.P Mittal and J.R.P Gupta, "Application of battery energy operated system to isolated power distribution systems", Proceedings of the $7^{\text {th }}$ international conference on power electronics and drive systems, Nov 2007, pp 526-532

[21] J.H. Lee, H.S. Bae, B.H. Cho, "Resistive Control for a Photovoltaic Battery Charging System Using a Microcontroller," IEEE Trans. on Industrial Electronics, vol. 55, no. 7, pp. 2767-2775, July 2008.

[22] L.-R. Chen, "Design of Duty-Varied Voltage Pulse Charger for Improving Li-Ion Battery-Charging Response," IEEE Trans. on Industrial Electronics, vol. 56, no. 2, pp. 480-487, Feb 2009.

[23] M. A. Alahmad, H. L. Hess, "Evaluation and Analysis of a New SolidState Rechargeable Microscale Lithium Battery," IEEE Trans. on Industrial Electronics, vol. 55, no. 9, pp. 3391-3401, Sept 2008.

[24] Yuang-Shung Lee, Wei-Yen Wang, Tsung-Yuan Kuo, "Soft Computing for Battery State-of-Charge (BSOC) Estimation in Battery String Systems," IEEE Trans. on Industrial Electronics, vol. 55, no. 1, pp. 229239, Jan 2008.

[25] M. Coleman, Chi Kwan Lee, Chunbo Zhu, W.G. Hurley, "State-ofCharge Determination From EMF Voltage Estimation: Using Impedance, Terminal Voltage, and Current for Lead-Acid and LithiumIon Batteries," IEEE Trans. on Industrial Electronics, vol. 54, no. 5, pp. 2550-2557, Oct 2007

[26] A. Burke, "Ultracapacitors: why, how and where is the technology", Journal of Power Sources, vol. 91, issue 1, pp $37-50,2000$.

[27] MATLAB Simulink SimPowerSystem, Available at: $\mathrm{http}: / /$ www.mathworks.com/products/simpower/

[28] T. Lambert, P. Gilman and P. Lilienthal, "Micropower system modeling with HOMER" available at: www.mistaya.ca/homer/MicropowerSystemModelingWithHOMER.pdf

[29] Aarthi Asok Kumar, "Technical and Economic Impacts of Distributed Generators and Energy Storage Devices on the Electric Grid", MS thesis, 2008, Electrical and Computer Engineering, Mississippi State University

[30] Prabha Kundur, "Power System Stability and Control", McGraw-Hill, 1994

[31] N. Mohan, T. M. Undeland and W. P. Robbins, "Power electronics converters, applications and design", John Wiley \& Sons, Third edition, 2007.

[32] An application note by Maxwell technologies, "How to determine the appropriate size ultracapacitor for your application", Technical Support, Maxwell Technologies

[33] T. Givler and P. Lilienthal, "Using HOMER ${ }^{\circledR}$ Software, NREL's Micropower Optimization Model, to Explore the Role of Gen-sets in Small Solar Power Systems", Technical Report NREL/TP-710-36774, May 2005

[34] A.S Malik and A. Awasanjli, "Energy fuel saving benefit of a wind turbine", Proceedings of the 12th IEEE Electrotechnical conference, vol. 3 pp1041-1044, May 2004.

[35] A. Gupta, R.P Saini and M.P Sharma, "Design of an Optimal Hybrid Energy System Model for Remote Rural Area Power Generation”, 
Received Date: Sept 16, 2010, Revised Date: May 7, 2011

Proceedings of the International conference on Electrical engineering, pp. 1-6, April 2007.

[36] Zia Haq, "Biomass for Electricity Generation in NEMS", Report by Office of Integrated Analysis and Forecasting, Energy Information Administration

Anurag K. Srivastava received his Ph.D. degree from Illinois Institute of Technology (IIT), Chicago, in 2005 and working as Assistant professor at Washington State University since 2010. He worked for five years as assistant research professor at Mississippi State University. His research interest includes power system stability/ security, microgrid, smart grid, real time simulation, electricity market and artificial intelligent application in power system. Dr. Srivastava is member of IEEE, IET, IEEE Power and Energy Society, Sigma Xi, ASEE and Eta Kappa Nu. He serves as chair of IEEE PES career promotion committee and secretary of student activities subcommittee.

Aarti Asok Kumar received her MS in Electrical Engineering from Mississippi State University in 2008 and B.E in Electrical \& Electronics Engineering from KCG College of Technology, Chennai, India in 2005. She is presently working with LCG consulting, California. Her areas of interests include power system stability and analysis, distributed generation impacts on the grid, power system operation and control, and power system modeling.

Noel N. Schulz received her Ph.D. in EE from the University of Minnesota in 1995 and currently working as Paslay Professor of Electrical and Computer Engineering at Kansas State University. She has served as faculty member at Mississippi State University and Michigan Tech in the past. Her research interests are in computer applications in power system operation including artificial intelligence techniques. She has been recently elected as PresidentElect of IEEE PES. She is recipient of the IEEE/PES Walter Fee Outstanding Young Power Engineer Award and member of IEEE, ASEE, SWE, Eta Kappa $\mathrm{Nu}$ and Tau Beta Pi. 